\title{
Blended learning in dentistry: 3-D resources for inquiry-based learning
}

\author{
Yanqi Yang \\ Orthodontics, Faculty of Dentistry \\ The University of Hong Kong, Hong Kong \\ E-mail: yangyanq@hku.hk
}

\section{Linkun Zhang}

Orthodontics, Faculty of Dentistry

The University of Hong Kong, Hong Kong

Orthodontics, Tianjin Stomatological Hospital of Nankai University, China

E-mail: zlkxjtu@163.com

\section{Susan Bridges*}

Dental Education and E-Learning, Faculty of Dentistry

The University of Hong Kong, Hong Kong

E-mail: sbridges@hku.hk

*Corresponding author

\begin{abstract}
Motivation is an important factor for inquiry-based learning, so creative design of learning resources and materials is critical to enhance students' motivation and hence their cognition. Modern dentistry is moving towards "electronic patient records" for both clinical treatment and teaching. Study models have long been an essential part of dental records. Traditional plaster casts are, however, among the last type of clinical record in the dental field to be converted into digital media as virtual models. Advantages of virtual models include: simpler storage; reduced risk of damage, disappearance, or misplacement; simpler and effective measuring; and easy transferal to colleagues. In order to support student engagement with the rapidly changing world of digital dentistry, and in order to stimulate the students' motivation and depth of inquiry, this project aims to introduce virtual models into a Bachelor and Dental Surgery (BDS) curriculum. Under a "blended" e-learning philosophy, students are first introduced to the new software then 3-D models are incorporated into inquiry-based problems as stimulus materials. Face-toface tutorials blend virtual model access via interactive whiteboards (IWBs). Students' perceptions of virtual models including motivation and cognition as well as the virtual models' functionality were rated after a workshop introducing virtual models and plaster models in parallel. Initial student feedback indicates that the 3-D models have been generally well accepted, which confirmed the functionality of the programme and the positive perception of virtual models for enhancing students' learning motivation. Further investigation will be carried out to assess the impact of virtual models on students' learning outcomes.
\end{abstract}

Keywords: Blended learning; Virtual model; Inquiry-based learning; Dental 
education; Motivation and cognition

Biographical notes: Dr. Yanqi Yang is a clinical assistant professor in orthodontics and Undergraduate Programme Director in orthodontics in Faculty of Dentistry, the University of Hong Kong. Her research interest is using virtual models in dental education.

Dr. Linkun Zhang is an honorary assistant professor in Faculty of Dentistry, the University of Hong Kong. His research interest is transformation of plaster models into virtual models.

Dr. Susan Bridges is currently Assistant Dean (Undergraduate Education) at the Faculty of Dentistry, The University of Hong Kong. Her work focuses on curriculum development, including e-learning initiatives, to enhance student learning outcomes. Her research interests are interactional and ethnographic exploring the "how" of effective pedagogy.

\section{Introduction}

Motivation and cognition are commonly modeled as distinct processes: motivation as some form of initiating and directing behavior, and cognition as the manipulation of encoded representations in memory (Bickhard, 2000). The two are generally regarded as closely associated with the stimulation of motivation considered leading to better learning outcomes. One of the tasks for academics engaged in teaching, therefore, is to create new materials through technology to stimulate students' motivation and hence cognition.

Referring to a principled mixing of different learning environments, a blended learning approach can combine face-to-face instruction with computer-mediated support. Learners and teachers work together to improve the quality of learning and teaching, with the ultimate aim of blended learning being to provide realistic practical opportunities for learners and teachers to make learning independent, useful, sustainable and ever growing (Graham, 2005).

Dentistry is a clinical discipline which integraties of science and art. One of the learning outcomes in Dentistry is to elicit and interpret clinical symptoms and signs by interviewing and examining patients systematically and with sensitivity, and to use this information to guide further investigations. If one considers pedagogy to be the art of teaching, then it is imperative for curriculum developers to design teaching materials with the organic combination of scientific data and artistic input. Such a creative approach to supporting student learning as a design process is key in maintaining a dynamic curriculum that is responsive to student interests. This attractiveness may assist in then stimulating students' motivation which will lead to satisfactory learning outcomes (Vattam et al., 2011; Kolodner et al., 2003). In the case presented here, the Faculty of Dentistry's vision for educational technologies is to adopt a blended approach to support interactive, small-group learning - both in problem-based learning (PBL) and clinical settings (Bridges, Botelho, \& Tsang, 2010). PBL in the Faculty of Dentistry is based on a series of carefully structured, integrated problems that allow students to be exposed to the main elements of basic biological, behavioral and social sciences that underpin dental surgery. In parallel to PBL, case-based learning (CBL) is adopted as a complementary pedagogy in Dentistry. Similarly to PBL, students work in groups and meet with a tutor in CBL tutorials from the 2nd year of the degree programme. In case-based discussions, students are expected to apply the knowledge and skills developed in PBL to the "real" 
clinical problem-solving context of a patient case. Both PBL and CBL are inquiry-based approaches which aim to facilitate students' active learning, i.e. raising questions, searching for answers and finally understanding and solving the problems.

The current approach to adopt blended learning gives a potential environment for students to learn more effectively in an inquiry-based curriculum. The learning management system has been fully operational and the recent introduction of interactive white boards (IWBs) has enabled seamless integration of face-to-face teaching and online support. The IWBs are providing the necessary infrastructure for real-time, large screen engagement with not only WebCT or Moodle resources, but also open-access and online resources and multimedia software. With IWBs, the innovative resources for PBL have been technologically upgraded to include interactive 3-D objects and in-house videos of clinical procedures using intra-oral cameras etc. High resolution radiographs and oral photographs are posted in the learning management system and students are able to manipulate these objects using zoom functions etc. to examine evidence in greater depth and with improved visual clarity (Bridges, Botelho, Green, \& Chau, 2012). Based on the progress, more digital learning resources are to be developed to enhance the use of blended learning in clinical learning.

Each generation is becoming increasingly interested in newly arising technologies and forms of visual representation, such as 3-D imaging. Three-D movies and 3-D games are attracting more young peoples' interest in their daily lives. At the same time, 3-D imaging in education is in extensive use in many disciplines, such as physics (Smithenry, 2009), medicine (Jang, 2010), and engineering design graphics (Krueger \& Barr, 2007). Modern dentistry is moving towards "electronic patient records". Similar to medicine, radiographs and photos are the important parts of patient records in dentistry. With the fast development of computer technology, digitalization of radiographs and photos has been commonly used for both clinical treatment and dental teaching. However, distinct from medicine, study models in dentistry are a unique but essential part of clinical records. Traditional plaster casts are, however, among the last type of clinical record in the dental field to be converted into digital media as virtual models (Redmond, 2001). In clinics, although more dentists are accepting the virtual record due to the advantages of digitalized models, some of them still prefer to touch the solid ones (Joffe, 2004). As for dental education, virtual models have not been a strong feature of the teaching and learning resources in dental field.

There are a few advantages with transforming solid models to virtual models as teaching and learning resources. With the virtual models, since students have increased access through digital archiving on the learning management system, they do have more mobility and flexibility by studying the 3-D models on computers and do not need to borrow and carry cumbersome plaster casts. Due to easier duplication, students will have individual access to a set of virtual models. Last but not least, by creating the learning resources of virtual models, students will gain experience with handling electronic data for dental record keeping. Therefore, in order to support student engagement with the rapidly changing world of digital dentistry, and in order to stimulate students' learning motivation, the project that we discuss in this paper introduced virtual models into a Bachelor of Dental Surgery (BDS) curriculum. A pilot evaluation collecting students' perceptions of virtual models was carried out to assess the effects of creating the new learning resources through the technology of transforming the solid materials into virtual ones, in an attempt to obtain basic feedback to inform planned further expansion of the resources. 


\section{Literature review}

\subsection{Blended learning and inquiry-based learning}

The idea of blending different learning experiences has been in existence for a long time. The infusion of web-based technologies into the learning and teaching process has recently brought this term into the limelight (Clark, 2003). Blended learning is often defined as the combination of face-to-face and online learning (Williams, 2002). To understand it in a wider view, it is also suggested that blended learning is an opportunity to redesign the way that courses are developed, scheduled and delivered in higher education through a combination of physical and virtual instruction, "bricks and clicks" (Bleed, 2001). The goal of these redesigned courses should be to join the best features of in-class teaching with the best features of online learning to promote active, self-directed learning opportunities for students with added flexibility (Garnham \& Kaleta, 2002). Based on this argument, Garrison and Vaughan (2008) stated that "blended learning is the organic integration of thoughtfully selected and complementary face-to-face and online approaches and technologies".

Since dentistry is a clinical discipline, a major aim of dental education is to foster students' ability to apply knowledge in subsequent clinical settings, i.e. inquiry-based learning. Studies have shown that the principle of adult learning requires active engagement in the learning process in order to achieve the desired educational outcome (Knowles, Holton, \& Swanson, 2005; Bransford, Brown, \& Cocking, 2000). Problembased learning (PBL) is a type of inquiry-based learning, which is an effective learning approach organized based on adult learning and constructivist theories (Norman \& Schmidt, 1992; Hmelo-Silver \& Eberbach, 2012). Students are provided with interesting, ill-structured problems and are guided through a process of activating prior knowledge and identifying knowledge gaps followed by independent research with final evaluation and synthesizing of information (Barrows 1985). This educational structure provides a foundation for critical thinking about new clinical situations encountered during patient care (Shuler, 2012). Incorporating blended learning into PBL is considered as part of the next generation of PBL mode (Howe \& Schnable, 2012; Bridges, Whitehill, \& McGrath, 2012).

\subsection{Virtual models}

Blended e-learning in dentistry relies on transformation of clinical evidence into virtual resources. Different to medical disciplines, where 2-D radiographs and photos can be more easily transformed into soft copies, 3-D dental models have long been an essential part of dental records. However, they are among the last type of clinical record in the dental field to be converted into digital media as virtual models (Redmond, 2001). Shortcomings of plaster models involve the difficulties with storage, retrieval, transferability and durability (Quimby, Vig, Rashid, \& Firestone, 2004), while advantages of virtual models include (1) simpler storage; (2) reduced risk of damage, disappearance, or misplacement; (3) simpler and more effective measuring; (4) easy transferal to colleagues, other specialists, and even patients (Redmond, 2001).

The concept of "digital" study models is not new. They appeared as 2D digital photographic representations using QuickCeph (QuickCeph Systems, San Diego, California, USA), which is based on digitally photographing the models in the 5 usual views (front, right and left lateral, and upper and lower occlusal) (Joffe, 2004). These digitally photographed "models" could then be stored, viewed (in the 5 views taken), and 
tooth widths digitized from the occlusal views for space assessment. It solved the storage problem, but it did not allow any manipulation of the models and assessment was limited (Joffe, 2004). In addition, the models had first to be cast and set up for the photographic input. Later holographic images were investigated (Rossouw, Benetar, Stander, \& Wynchank, 1991; Martensson \& Ryden, 1992). However, most early technologies required complex capture equipment and proved costly. Laser technology is also limited in capturing areas between adjacent teeth, which are overlapping. Scanning technology has been available since the mid 1990s, and software development over the past 5-6 years has refined this approach dramatically. These advances have made the capture of scanned-in images commercially viable and it is this computer-aided design (CAD) technology that is now used to produce digital study casts (Joffe, 2004).

Plaster models are records showing tooth dimensions as well as intra- and interarch relationships (Bell, Ayoub, \& Siebert, 2003). In inter- or intra-arch relationship measurement (Terai, Shimahara, Sakinaka, \& Tajima, 1999; Bell, Ayoub, \& Siebert, 2003; DeLong, Heinzen, Hodges, Ko, \& Douglas, 2003; Santoro, Galkin, Teredesai, Nicolay, \& Cangialosi, 2003; Quimby et al., 2004; Costalos, Sarraf, Cangialosi, \& Efstratiadis, 2005; Okunami et al., 2007) or in tooth dimension measurement (Bell, Ayoub, \& Siebert, 2003; Quimby et al., 2004; Mayers, Firestone, Rashid, \& Vig, 2005; Paredes, Gandia, \& Cibrian, 2006; Stevens et al., 2006; Asquith, Gillgrass, \& Mossey, 2007; Mullen, Martin, Ngan, \& Gladwin, 2007; Lee, Delong, Hodges, Hayashi, \& Lee, 2008), no significant difference has been found between virtual models and their corresponding plaster models. A comprehensive assessment of "the level of agreement" between plaster and virtual models reported by Bootvong et al. (2010), provided important evidence to support the use of virtual models in clinical practice; they concluded that the analysis performed on virtual models is as valid as traditional plaster models for intra- and inter-arch relationship.

\subsection{3-D resources in education}

3-D imaging is in extensive use in education across many disciplines, such as physics (Smithenry, 2009), medicine (Jang, 2010), and engineering design graphics (Krueger \& Barr, 2007). 3-D MUVEs was used in an online problem-based learning context and was found to be beneficial to the learning (Omale, 2010). Internal anatomical parts of the human body can be shown clearly by a 3-D model for anatomy curricula (Jang, 2010). However, in the dental field, 3-D models have not been used in dental education as they are the latest records to be digitalized and are still a relatively new innovation in dental clinics. Therefore, using virtual models as a learning resource in dental teaching is open for investigation, and the effects of incorporating virtual models into dental blended learning remains unknown.

\section{Project background}

Drawing on the existent infrastructure using the current learning management system and IWBs in blended learning, this project aims to expand the affordances of blended learning in an inquiry-based curriculum by providing additional 3-D resources for problem- and case-based discussions. With development of virtual reality digital resources for dental problem- and case-based scenarios, the project has capitalized upon recent e-learning initiatives and closely integrated these with the PBL and CBL methodologies. 
This project employs a standard learning management system (LMS) to support dentally-relevant case scenarios. Virtual models, high resolution radiographs and oral photographs are posted in the learning management system as inquiry materials to scaffold learner engagement with the problem at hand (Hmelo-Silver, Duncan, \& Chinn, 2007). Transforming the original plastic models to virtual models was the key stage of resource development. Impressions or plaster models were sent to the outsource company who provides the service for transforming the virtual models.

There are 14 tutorial rooms equipped with an interactive whiteboard package (board, laptop \& projector) are provided to facilitate small group teaching and discussion. Using these resources, facilitators and students can access, view and manipulate digital case records including the 3-D virtual models (Fig. 1) and other digital learning objects on a large screen for whole group discussion (Bridges, Botelho, \& Tsang, 2010). For this project, each laptop was installed with the requisite software for manipulating virtual models. The software O3DM ${ }^{\circledR}$ was also uploaded to the learning management system for students to download freely with permission from the designers.

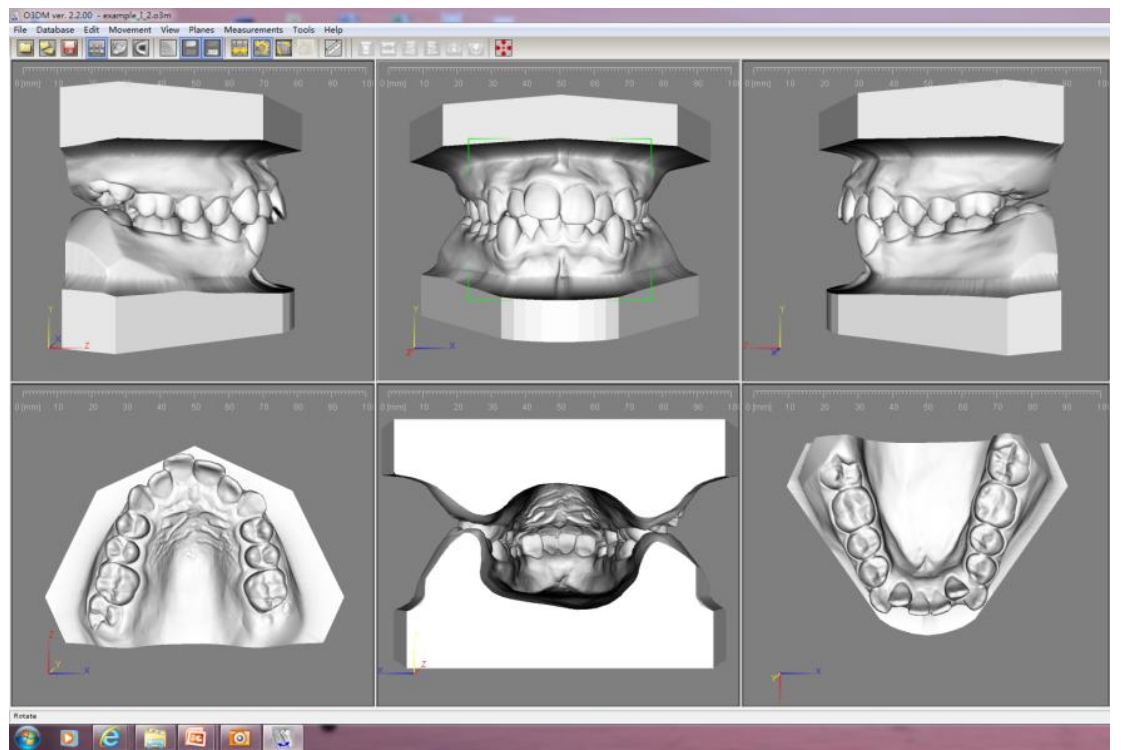

Fig. 1. Virtual models showing teeth and adjacent structures from different views

To evaluate the project, the research question "Can virtual models help to motivate student learning in dentistry?" was asked. Before we answer this question through assessment, the first step is to evaluate whether the students perceive that introduction of virtual models into dental education as helpful for their learning. The positive feedback from the students would indicate that the virtual models can stimulate their learning motivation. This is the basis for enhancement of cognition and learning outcomes. Therefore, assessment of the students' perception was set as the first step in a preliminary evaluation. 


\section{Preliminary evaluation}

\subsection{Evaluation method}

As the preliminary evaluation, students' perceptions of virtual models for dental elearning were gathered. In order to avoid bias, the evaluation targeted students who did not have any prior experience in either of plaster models or virtual models. Both plaster models and virtual models were introduced to 118 students in a half-day, hands-on, introductory workshop. In this workshop, the students were given the task to analyze a case with severe maxillofacial deformity, tooth malalignment and malocclusion. Plaster models and virtual models of the same case were given to the students. The students were instructed to analyze the tooth alignment problem, crowding and space, intermaxillary relationship of the case and to plan the treatment options. They were asked to show their results drawn from plaster casts on paper and results drawn from virtual models on computer screens. The participants were required to complete an original questionnaire survey with simple questions generated based on the basic features of virtual models immediately after the workshop. With the questionnaire, the students were instructed to rate the 7 items regarding virtual models on a 5-score scale with 1 as strongly disagree and 5 as strongly agree. The preference of the type of models was also asked in the questionnaire survey.

\subsection{Evaluation results and discussion}

Observations by the teaching team during task performance noted that task completion was satisfactory with both plaster models and virtual models. All the 118 students completed and returned the questionnaires.

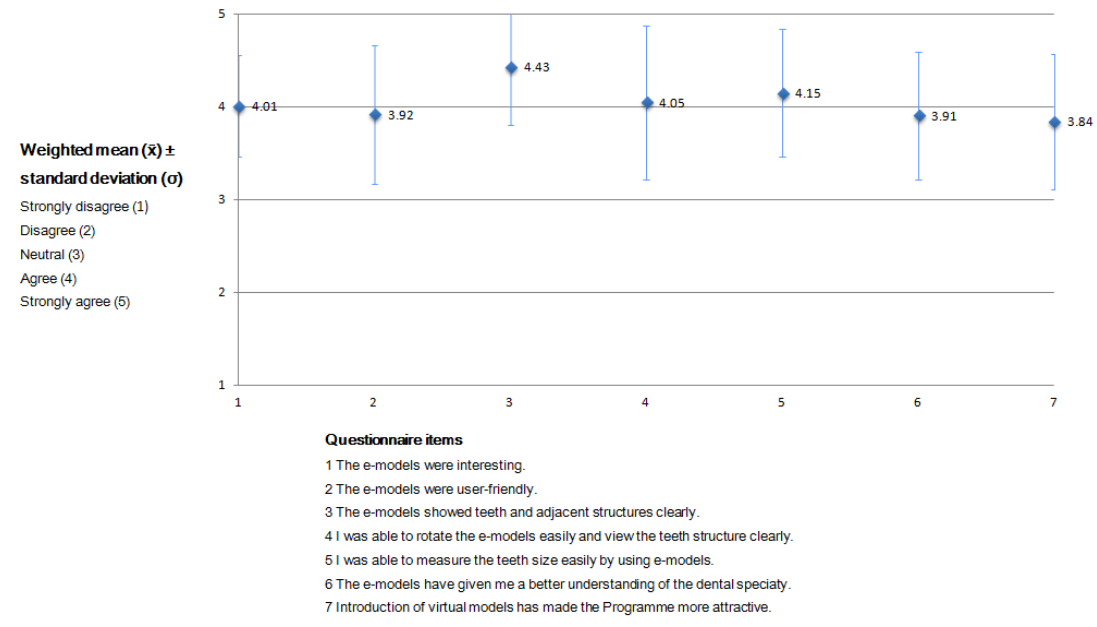

Fig. 2. Students' ratings of virtual models

\subsubsection{Overall impression}

The original questionnaire explores students' perceptions of virtual models. The mean scores for rating all the 7 items regarding virtual models were above 3.8 (Fig. 2). The mean scores of the 7 items regarding the virtual models were as follows: "virtual models show teeth clearly" (4.43 \pm 0.62$)$, "virtual models make teeth measurement more easily" 
(4.15 \pm 0.69$)$, "virtual models can be rotated more easily" (4.05 \pm 0.83$)$, "virtual models are interesting" (4.01 \pm 0.55$)$, "virtual models are user-friendly" (3.92 \pm 0.75$)$, "virtual models make the dental specialty better understood" (3.91 \pm 0.69$)$, and "virtual models make the program more attractive" (3.84 \pm 0.73$)$.

The mean scores for all the questions were closer to 4 as "agree" which indicated the highly positive feedback of the virtual models from the students. The questions cover the effects of virtual models on students' motivation and the functionality of virtual models, etc., which will be discussed in depth below.
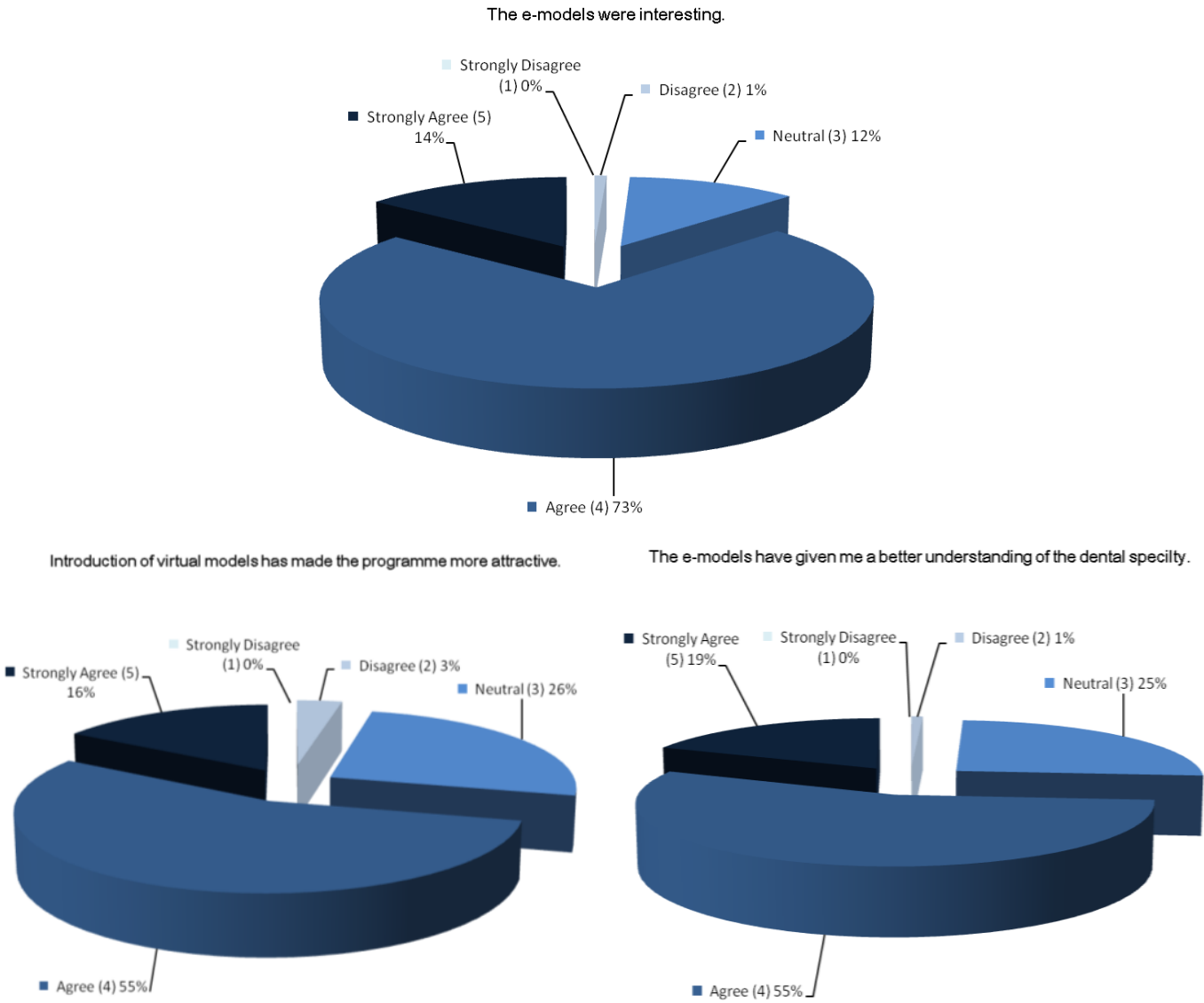

Fig. 3. Students' perceptions of virtual models: Motivation and cognition

\subsubsection{Students' motivation and cognition}

As is shown in Fig. 3, 87.3\% of students agreed or strongly agreed that the virtual models were interesting. Over two thirds of students thought that introduction of virtual models made the programme more attractive. The results indicate that most students were positively disposed towards accepting virtual models as a learning resource. Generally, young people usually are open and interested in innovation. Being very familiar with 3-D videos and 3-D games, not surprisingly, they are interested in the virtual models which are also derived from 3-D technology. Interest promotes learning motivation, and motivation benefits cognition. At the same time, the 3-D demonstrations with virtual 
models also contributed to clearer interpretation of the academic knowledge. This, we argue, can also contribute to improved cognition as evident in the results showing. That over $70 \%$ of students thought that the virtual models support understanding of dentistry for beginners (Fig. 3).

\subsubsection{Functionality}

$81.4 \%$ of students thought (agreed or strongly agreed) that the virtual models were userfriendly. Most of the students $(94.9 \%)$ agreed or strongly agreed that the virtual models showed teeth and adjacent structures clearly. $86 \%$ of students agreed or strongly agreed that they were able to rotate the e-models easily and view the teeth structure clearly. Over $75 \%$ of the students thought (agreed or strongly agreed) that the teeth size could be easily measured using e-models. (Fig. 4).
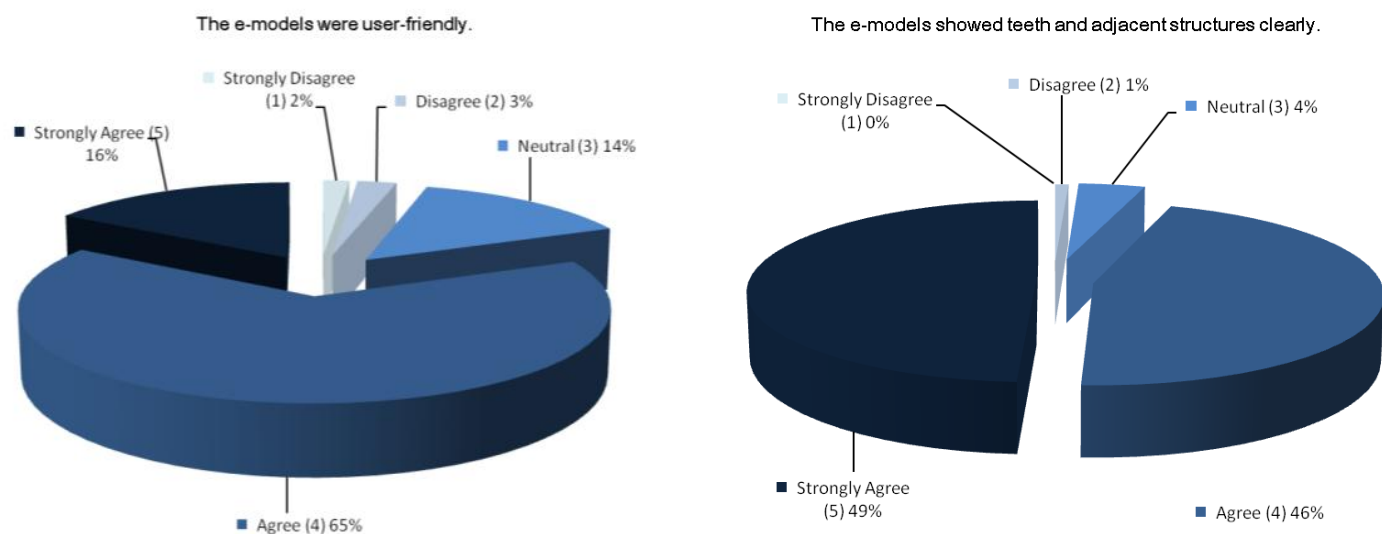

I was able to rotate the e-models easily and view the teeth structure clearly.

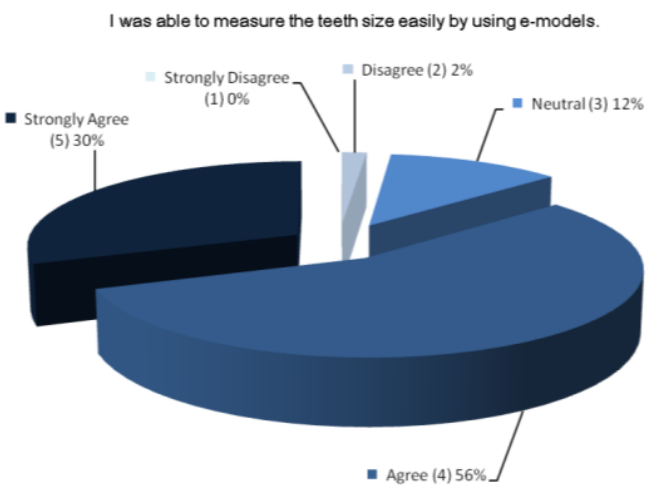

Fig. 4. Students' perceptions of virtual models' functionality

Regarding the virtual models' functionality, on one hand, it depends on the software design as to whether they are really user-friendly. On the other hand, it is related to the users' ability to manipulate the computerized resources. The positive results indicate that the virtual models were easily manipulated, which confirmed the userfriendly design. At the same time, the background of the current young generation's 
familiarity with computer manipulation and information technology can also be considered as a contributing factor.

\subsubsection{Transition phase in adaption of new technologies}

Survey data indicated that, in comparing plaster casts and virtual models, $9.3 \%$ students preferred plaster casts, $11.9 \%$ of them preferred virtual models, and $78.8 \%$ would like to use both together (Fig. 5). This result may indicate a need for a transition when moving from solid to virtual learning materials. Significantly for dentistry, it may also indicate the necessity to maintain a blended approach to resources with solid materials being made available for development of requisite fine motor skills in getting a creative "feel" for the clinical orthodontic problem at hand. However, the imperative to adapt to changing workplace demands in modern dentistry is seen in the result that virtual dental models are gradually becoming more prevalent (Redmond, 2001). This change, although meeting opposition from conservative dentists who want to "feel" the plaster models in their hands, has considerable advantages (Dalstra \& Melsen, 2009), especially in the era of the "electronic patient record" when all patient information will be stored digitally. The advantages involve obviating the need for extensive storage facilities, reducing the risk of physical damage and/or the disappearance of the casts stored in the wrong location. In addition, there is the possibility of sharing the models with other colleagues. This point is especially important and beneficial for introducing virtual models into dental education In the era of the "electronic patient record", when all patients' information will be stored digitally, virtual model systems will become the norm.

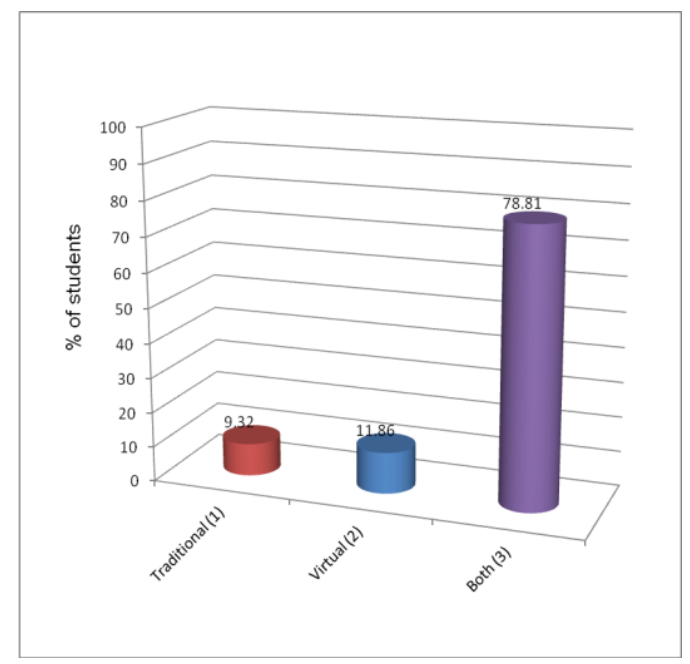

Fig. 5. Students' preferred type of study models

A recent interactional ethnography (Bridges, Whitehill, \& McGrath, 2012), researching third year undergraduate dental students' use of resources across a PBL problem cycle found the application of the blended curriculum design clearly supported student learning as these students "seamlessly engaged with multiple physical and virtual materials of representation as part of their PBL process" with the "intervisual relations" of various multimodal resources acting "to support and enhance collective and individual cognition" (p. 120). The authors argued that such a blended approach supported modern theories of semiosis both in terms of multimodality and social constructivist principles of knowledge construction through the appropriation of mediating tools. Results from the 
above student survey on the use of 3-D learning objects in the same learning context support this argument. Students perceived value in accessing and manipulating both virtual and solid models as tools to support individual and collective knowledge construction. Not only was this seen in terms of value-addedness, but significantly as core to knowledge acquisition where "the appropriation of mediating tools was dependent on their relevance to new knowledge" (ibid). The student perception data above reflects the fine-grained ability of undergraduate dental students to weave between modalities as necessary for their own learning. Students in both studies could be viewed as critical consumers of the materials provided in appropriating them to meet their learning outcomes.

\subsubsection{Implications to the inculcation of creativity through technology}

This case study introduces virtual models as a learning resource for inquiry-based learning in dentistry. After introducing the relatively new technology of virtual models into dental education students' positive feedback indicated perceived enhancement of their learning motivation with perceived improvement in cognition.

The current pilot study just preliminarily assessed the students' perceptions of the characteristics of virtual models. The pilot work has set up the technology introducing the virtual models into blended learning in dentistry as part of a larger project using virtual models in blended learning to enhance the students' cognition. Further evaluation is currently underway to examine how 3-D models support student engagement, cognition and the achievement of student learning outcomes in inquiry-based learning in a clinical curriculum.

\section{Conclusions and remarks}

Students responded positively to the incorporation of virtual models in the early years of dental education; however, they strongly preferred a blended approach introducing both solid and virtual models simultaneously.

Dentistry is a clinical discipline with the integration of "art \& science", so a major aim of dental education in the pre-clinical stage is to let students gain artistic sensibilities in feeling and visualizing clinical problems. It is anticipated that these creative skills will then be used in applying knowledge in subsequent clinical settings through inquiry-based learning. As motivation is an important factor for inquiry-based learning, educators' creativity and design of learning resources and materials are critical to enhance the students' motivation and hence their cognition. An additional impetus for change comes from workforce demands. Given the rapid development of computer technologies, the digital dentistry movement can be viewed as an inevitable trend. Dental practice innovations in "electronic patient records" meet current demands for digital records as a practical and efficient solution to data storage and access. Virtual learning resources, therefore, are creative motivators for 21 st century digital learners in clinical dentistry and provide a creative challenge for their curriculum developers. 


\section{Acknowledgements}

The project was support by a Teaching Development Grant, the University of Hong Kong. Thanks to O3DM for free use of the software for teaching purposes and thanks to Ms. Rita Suen for research assistance.

\section{References}

Asquith, J., Gillgrass, T., \& Mossey, P. (2007). Three-dimensional imaging of orthodontic models: A pilot study. European Journal of Orthodontics, 29, 517-522.

Barrows, H. S. (1985). How to design a problem-based curriculum for the preclinical years (Vol. 8). New York: Springer Publishing Company Inc.

Bell, A., Ayoub, A., \& Siebert, P. (2003). Assessment of the accuracy of a three dimensional imaging system for archiving dental study models. Journal of Orthodontics, 30, 219-223.

Bickhard, M. H. (2000). Motivation and emotion: An interactive process model. In R. D. Ellis \& N. Newton (eds.), The Caldron of Consciousness (pp. 161-178). Amsterdam, Netherlands: John Benjamins Publishing Company.

Bleed, R. (2001). A hybrid campus for a new millennium. Educause Review, 36(1), 1624.

Bootvong, K., Liu, Z., McGrath, C., Hägg, U., Wong., R. W. K., Bendeus, M., \& Yeung, S. (2010). Virtual model analysis as an alternative approach to plaster model analysis: reliability and validity. European Journal of Orthodontics, 32, 589-595.

Bransford, J. D., Brown, A. L., \& Cocking, R. R. (Eds.). (2000). How people learn: Brain, mind, experience and school. Washington, DC: National Academy Press.

Bridges, S. M., Botelho, M. G., \& Tsang, C. S. P. (2010). BPL2.0: Blending learning for an interactive, problem-based pedagogy. Medical Education. 44, 11.

Bridges, S., Botelho, M., Green, J. L., \& Chau, A. C. M. (2012). Multimodality in problem-based learning (PBL): An interactional ethnography. In S. Bridges, C. McGrath, \& T. L. Whitehill (eds.), Problem-Based Learning in Clinical Education (pp. 99-120). Netherlands: Springer.

Bridges, S., Whitehill, T. L., \& McGrath, C. (2012). The next generation: Research directions in PBL. In S. Bridges, C. McGrath, \& T. L. Whitehill (eds.), Problembased learning in clinical education: The next generation (pp. 225-231). Dordrecht: Springer.

Clark, D. (2003). Blend it like Beckham. Epic Group PLC. Retrieved from: http://www.epic.co.uk/content/resources/white papers/blended.htm.

Costalos, P., Sarraf, K., Cangialosi, T., \& Efstratiadis, S. (2005). Evaluation of the accuracy of digital model analysis for the American Board of Orthodontics objective grading system for dental casts. American Journal of Orthodontics and Dentofacial Orthopedics, 128, 624-629.

Dalstra, M., \& Melsen, B. (2009). From alginate impressions to digital virtual models: accuracy and reproducibility. Journal of Orthodontics, 36, 36-41.

DeLong, R., Heinzen, M., Hodges, J., Ko, C., \& Douglas, W. (2003). Accuracy of a system for creating 3D computer models of dental arch. Journal of Dental Research, $82,438-442$.

Garnham, C., \& Kaleta, R. (2002). Introduction to hybrid courses. Teaching with Technology Today, 8 (6). Retrieved from: http://www.uwsa.edu/ttt/articles/garnham.htm. 
Garrison, D. R., \& Vaughan, N. D. (2008). Blended learning in higher education. San Francisco: Jossey-Bass.

Graham, C. R. (2005). Blended learning systems: Definition, current trends, and future directions. In C. J. Bonk \& C.R. Graham (eds.), Handbook of blended learning: Global perspectives, local designs (pp. 3-21). San Francisco, CA: Pfeiffer.

Hmelo-Silver, C. E., \& Eberbach, C. (2012). Learning theories and problem-based learning in clinical education. In S. Bridges, C. McGrath, \& T. L. Whitehill (eds.), Problem-Based Learning in Clinical Education (pp. 3-17). Netherlands: Springer.

Hmelo-Silver, C. E., Duncan, R. G., \& Chinn, C. A. (2007). Scaffolding and achievement in problem-based and inquiry learning: A response to Kirschner, Sweller, and Clark (2006). Education Psychology, 42, 99-107.

Howe, E. L. C., \& Schnabel, M. A. (2012). The changing face of problem-based learning: social networking and interprofessional collaboration. In S. Bridges, C. McGrath, \& T. L. Whitehill (eds.), Problem-Based Learning in Clinical Education (pp. 121-137). Netherlands: Springer.

Jang, S. (2010). From vesalius to virtual reality: How embodied cognition facilitates the visualization of anatomy. ProQuest LLC, Ph.D. Dissertation, Columbia University.

Joffe, L. (2004). Current products and practices Ortho CADTM: Digital models for a digital era. Journal of Orthodontics, 31, 344-347.

Knowles, M. S., Holton, E. F., \& Swanson, R. A. (2005). The adult learner. San Diego: Elsevier.

Kolodner, J. L., Camp, P. J., Crismond, D., Fasse, B., Gray, J., Holbrook, J., Puntambekar, S., \& Ryan, M. (2003). Problem-based learning meets case-based reasoning in the middle-school science classroom: putting learning by Design (tm) into practice. Journal of the Learning Sciences , 12(4) , 495-547.

Krueger, T. J., \& Barr, R. E. (2007). The concurrent engineering design paradigm is now fully functional for GraphicsEducation. Engineering Design Graphics Journal, 71(1), $22-28$.

Lee, S., Delong, P. R., Hodges, J. S., Hayashi, K., \& Lee, J. B. (2008). Predicting first molar width using virtual models of dental arches. Clinical Anatomy, 21, 27-32.

Mayers, M., Firestone, A., Rashid, R., \& Vig, K. (2005). Comparison of peer assessment rating (PAR) index scores of plaster and computer-based digital models. American Journal of Orthodontics and Dentofacial Orthopedics, 128, 431-434.

Martensson, B., \& Ryden, H. (1992). The holodent system, a new technique for measurement and storage of dental casts. American Journal of Orthodontics and Dentofacial Orthopedics, 102, 113-119.

Mullen, S., Martin, C., Ngan, P., \& Gladwin, M. (2007). Accuracy of space analysis with emodels and plaster models. American Journal of Orthodontics and Dentofacial Orthopedics, 132, 346-352.

Norman, G. R., \& Schmidt, H. G. (1992). The psychological basis of problem-based learning: A review of the evidence. Academic Medicine, 67, 557-565.

Okunami, T., Kusnoto, B., BeGole, E., Evans, C., Sadowsky, C., \& Fadavi, S. (2007). Assessing the American Board of Orthodontics objective grading system: Digital vs plaster dental casts. American Journal of Orthodontics and Dentofacial Orthopedics, $131,51-56$.

Omale, N. M. (2010). Exploring the use of three-dimensional multi-user virtual environments for online problem-based learning. ProQuest LLC, Ed.D. Dissertation, Northern Illinois University.

Paredes, V., Gandia, J., \& Cibrian, R. (2006). Determination of Bolton tooth-size ratios by digitization, and comparison with the traditional method. European Journal of Orthodontics, 28, 120-125. 
Quimby, M., Vig, K., Rashid, R., \& Firestone, A. (2004). The accuracy and reliability of measurements made on computer-based digital models. Angle Orthodontist ,74, 298303.

Redmond, W. R. (2001). Digital models: A new diagnostic tool. Journal of Clinical Orthodontics, 35, 386-387.

Rossouw, P. E., Benetar, M., Stander, I., \& Wynchank, S. (1991). A critical comparison of three methods for measuring dental models. Journal of the Dental Association of South Africa, 46, 223-226.

Santoro, M., Galkin, S., Teredesai, M., Nicolay, O. F., \& Cangialosi, T. J. (2003). Comparison of measurements made on digital and plaster models. American Journal of Orthodontics and Dentofacial Orthopedics, 124, 101-105.

Shuler, C. F. (2012). Comparisons in basic science learning outcomes between students in PBL and traditional dental curricula at the same dental school. In S. Bridges, C. McGrath, \& T. L. Whitehill (eds.), Problem-Based Learning in Clinical Education. chapter 3. Netherlands: Springer.

Smithenry, D. W. (2009). Teaching with crystal structures: Helping students recognize and classify the smallest repeating particle in a given substance. Science Teacher, 76 (6), 52-57.

Stevens, D. R., Flores-Mir, C., Nebbe, B., Raboud, D. W., Heo, G., \& Major, P. W. (2006). Validity, reliability, and reproducibility of plaster vs digital study models: comparison of Peer Assessment Rating and Bolton analysis and their constituent measurements. American Journal of Orthodontics and Dentofacial Orthopedics, 129, 794-803.

Terai, H., Shimahara, M., Sakinaka, Y., \& Tajima, S. (1999). Accuracy of integration of dental casts in three-dimensional models. Journal of Oral Maxillofacial Surgery, 57, 662-665.

Vattam, S. S., Goel, A. K., Rugaber, S., Hmelo-Silver, C. E., Jordan, R., Gray, S., \& Sinha, S. (2011). Understanding complex natural systems by articulating structurebehavior-function models. Educational Technology \& Society, 14(1), 66-81.

Williams, C. (2002). Learning on-line: A review of recent literature in a rapidly expanding field. Journal of Further and Higher Education, 26(3), 263-272. 